${ }^{2}$ Blecher TE, Soothill JE, Voyce MA, Walker WHC. Antibody deficiency syndrome: a case with normal immunoglobulin levels. Clin Exp Immunol 1968;3:47-56.

${ }^{3}$ Corry JM, Polhill RB, Edmands SR, Johnston RB. Activity of the alternative complement pathway after splenectomy: comparison to activity in sickle cell disease and hypogammaglobulinemia. J Pediatr 1979;95:964-9.

4 Stevens R, Dichek D, Keld B, Heiner D. $\operatorname{IgG}_{1}$ is the predominant subclass of in vivo- and in vitro-produced antitetanus toxoid antibodies and also serves as the membrane IgG molecule for delivering inhibitory signals to anti-tetanus toxoid antibody-producing cells. J Clin Immunol 1983;3:65-9.
${ }^{5}$ Saxon A, Kobayashi RJ, Stevens RH, Singer AD, Stiehm ER, Siegel SC. In vitro analysis of humoral immunity in antibody deficiency with normal immunoglobulins. Clin Immunol Immunopathol 1980;17:235-44.

${ }^{6}$ Hammarström L, Granström M, Oxelius VA, et al. IgG subclass distribution of antibodies against $\mathrm{S}$. aureus, teichoic acid and $\alpha$-toxin in normal and immunodeficient donors. Clin Exp Immunol 1985; (in press).

Correspondence to Dr A Plebani, Clinica Pediatrica, Università di Pavia, 27100 Pavia, Italy.

Received 24 January 1985

\title{
Parents' understanding of coeliac disease and diet
}

\author{
P T JACKSON, J F T GLASGOW, AND R THOM
}

Department of Child Health, Queen's University of Belfast and Dietetic Department, Royal Belfast Hospital for Sick Children

SUMmary Parents of 50 children with coeliac disease were questioned about their knowledge of the disorder and the child's dietary compliance. Twenty of 50 parents admitted that compliance was less than strict. This correlated with poor knowledge of the disease which in turn was related to the family's social status. Membership of the Coeliac Society (23 of 50) correlated with both parental understanding and dietary compliance. Greater emphasis on dietary compliance and education of parents and patients is required.

Childhood coeliac disease requires a strictly kept gluten free diet for initial catch up growth and long term health and prevention of nutritional deficiencies $^{1}$ and possibly malignancy in later life. ${ }^{24}$ Few dietary studies have been conducted into childhood coeliac disease, and none into parent's understanding of the disorder or the effort directed towards dietary compliance.

\section{Patients and methods}

Fifty children (29 girls) with coeliac disease were studied at 1.5 to 19 (median 9.9 ) years of age. The diagnosis had been made on the basis of severe villus atrophy on jejunal histology and good clinical response to a gluten free diet. ${ }^{4}$ Where these two criteria applied no further biopsies were done. Patients and parents had been counselled by medical and dietetic staff both at diagnosis and at regular long term review.
A questionnaire was given to the parent who attended with the patient for clinical review. Questions were designed to test knowledge of the disease and the gluten free diet, probe attitudes and motivation, and determine the degree of dietary compliance. The family's social index ${ }^{5}$ was determined from information about parental education, work, housing, and family size. A clinical examination including measurement of height and weight was carried out, blood samples were taken to assess nutritional indices, and clinical information was abstracted from the patient's past medical records.

\section{Results}

Twenty nine families belonged to the registrar general's social class IV or V, 21 to class II or III. Only five parents had attained the GCE ordinary level examination standard or higher.

Dietary compliance. Parents were asked whether the diet was being kept and were given three optionsstrictly maintained (30 patients); broken regularly or sometimes (18); diet kept poorly or ignored (2). Dietary compliance was unrelated to the child's sex or current age, age at diagnosis, time since diagnosis, presence of a family history of coeliac disease ( 9 children), or presence of only one parent at home (11 families). Before the beginning of this study, eight patients had required a 'compliance' biopsy because of serious doubts about dietary compliance, and six of these admitted during the study that dietary compliance was still less than strict $(\mathrm{P}<0 \cdot 07)$. 
Parental knowledge. This was measured by asking the following eight questions and awarding a mark for each correct response: (1) spell 'coeliac' (correct in 16); (2) part of the body principally affected (27); (3) effect upon that part (33); (4) does it 'run in families?' (23); (5) is it a life long disease? (3); (6) substance that should be avoided (41); (7) in which flours is gluten present? (27); (8) gluten is a constituent of fat, carbohydrate, or protein? (8). The knowledge score correlated with the social index $(\mathrm{P}<0 \cdot 0006)$, but not with sex, age at study or at diagnosis, or current height or weight standard deviation scores. The parents of eight children who had required a 'compliance' biopsy, had a score between 0 and $4(\mathrm{P}<0.07)$ (Table 1$)$; the 17 with a score of 5 to 8 were each complying strictly with the diet $(\mathrm{P}<0.001)$ (Table 2).

Parental attitudes. Sixteen parents thought the gluten free diet was relatively easy to maintain-34 thought it more difficult (Table 2). It was significant that six of eight children who had required a 'compliance' biopsy were in the former group $(\mathrm{P}<0.015)$. Twenty three parents were members of the Coeliac Society and regularly received its literature. Membership correlated with the social index $(P<0.05)$, knowledge score $(P<0.005)$, and dietary compliance $(\mathrm{P}<0 \cdot 0001)$. Twenty four parents did not possess a current list of gluten free products and had a lower knowledge score $(\mathrm{P}<0.03)$ (Table 2).

Gluten free diet. Twenty six parents baked gluten free bread, cakes, and biscuits but eight never ate

Table 1 Knowledge score distribution of 50 parents of coeliac patients in relation to 'compliance' biopsy (CB)

\begin{tabular}{lllrrrrrr}
\hline Score & 1 & 2 & \multicolumn{1}{c}{3} & \multicolumn{1}{c}{4} & 5 & 6 & 7 & 8 \\
\hline Parents (\%) & 8 & 8 & 20 & 30 & 16 & 8 & 2 & 8 \\
Not undergoing CB & 1 & 1 & 3 & 3 & & & & \\
\hline
\end{tabular}

gluten free bread. Twenty nine children regularly took school meals but only 19 of the parents had discussed the diet with the school's catering staff. When asked, however, about the presence or absence of gluten in 14 commonly used foods, the percentage of parents answering correctly was as follows-spaghetti 70 , chocolate 84 , semolina 36 , Cornflakes 90, Weetabix 88, Rice Krispies 84, cheese 94 , custard 76 , potatoes 98 , doughnuts 94 , meringues 86 , carrots 98 , all ice-creams 74 , all potato crisps 86 .

Laboratory findings. Altogether $64 \cdot 3 \%$ whose current weight was less than the 25 th centile had an IgG value less than $9.7 \mathrm{~g} / 1$ compared with $26.3 \%$ of patients whose weights were above this. No other laboratory test correlated with knowledge score, height or weight centiles, or a 'compliance' biopsy.

\section{Discussion}

Continued gluten ingestion, well recognised in adults, ${ }^{3}$ also occurs in childhood coeliac disease. Congdon and colleagues ${ }^{6}$ found that only 10 of 32 children complied with the gluten free diet, that the most accurate method of identifying non-compliers, apart from biopsy, was by dietary questioning, and that this was superior to biochemical tests. We have corroborated these findings and shown that $40 \%$ of patients were not complying with the diet despite counselling at the time of diagnosis and at regular review appointments.

Poor dietary compliance, although not associated with symptoms or more than slight laboratory abnormalities, was closely linked to a poor parental knowledge of and attitude to coeliac disease and its management. Efforts to improve knowledge of the disease from an early stage may improve motivation and compliance and membership of the Coeliac Society could do likewise. Closer liaison between medical and dietetic staff and more discussion of dietary details with parents (and patients) is clearly necessary. This discussion needs to be at an appropri-

Table 2 Parental knowledge in relation to aspects of dietary management in coeliac disease

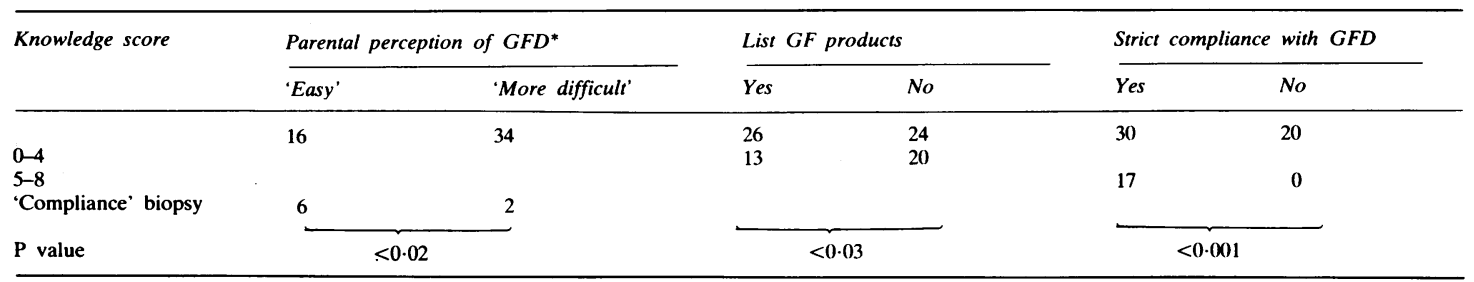

*Note the curious findings with regard to perception of the diet and 'compliance' biopsy.

$\mathrm{GFD}=$ gluten free diet; $\mathrm{GF}=$ gluten free. 
ate level, bearing in mind social class and education. It seems inadequate merely to ask whether parents are coping well with the diet since there was a curious disparity between their perception of the diet and their ability to ensure compliance. While the proportion of non-compliers has been relatively large in this survey, it is important to emphasise the comparatively disadvantaged nature of the social group. Our findings, therefore, may not be readily applicable in other communities where families may be more affluent and parents better informed. Nonetheless, it is salutory to reflect upon the proportion of patients who, in spite of regular dietetic counselling, seem unable to comply with the diet, the reasons for which seem largely social and educational.
References
1 Booth CC. The enterocyte in coeliac disease-1. Br Med J
1970;iv:1.
2 Cooke WT, Holmes GKT. Malignancy. Coeliac disease. Edin-
burgh: Churchill Livingstone, 1984:172-96.
Baker PG, Barry RE, Read AE. Detection of continuing gluten
ingestion in treated coeliac patients. Br Med J 1975;i:486-8.
4 Meeuwisse G. Diagnostic criteria in coeliac disease. Acta
Paediatr Scand 1970;59:461-3.
5 Osborn A, Morris T. The rationale for a composite index of
social class and its evaluation. Br J Sociol 1979;1:30.
6 Congdon P, Mason MK, Smith S, Crollick A, Steel A,
Littlewood J. Small bowel mucosa in asymptomatic children
with coeliac disease. Am J Dis Child 1981;135:118-21.

Correspondence to Dr J F T Glasgow, Department of Child Health, Institute of Clinical Science, Grosvenor Road, Belfast BT12 6BJ.

Received 25 February 1985

\section{Prevention of spread of echovirus 6 in a special care baby unit}

\section{J CAROLANE, A M LONG, P A MCKEEVER, S J HOBBS, AND A P ROOME}

Departments of Child Health and Histopathology, Bristol Maternity Hospital, and Joint Regional Public Health and District Virus Laboratory, Bristol.

SUMMARY A case of fatal neonatal infection with enteric cytopathogenic human orphan virus (echovirus) type 6 is presented. The measures taken to prevent further spread of infection with special reference to the use of human normal immunoglobulin are described.

Since the 1960 s enteric cytopathogenic human orphan viruses (echoviruses) have been associated with a spectrum of illness in neonates, ranging from milder disease through respiratory infections, meningitis, 'sepsis', to fulminant fatal disease. Although type 11 virus $^{1}$ predominates, others, including type 6 , have been implicated..$^{2-4}$

Outbreaks of infection have occurred in special care baby units where the virus has been introduced by an infected mother. ${ }^{15}$ She or other family members may ${ }^{35}$ or may not have symptoms.

We report a fatal echovirus type 6 infection in a neonate and describe measures taken to prevent spread in the special care unit including the use of human normal immunoglobulin prophylaxis.

\section{Case report}

A girl weighing $2150 \mathrm{~g}$, born by normal delivery at
35 weeks' gestation to a healthy mother, developed transient respiratory distress which resolved by the third day. Then, fully bottle fed, she was transferred to the transitional care ward to be with her mother.

On day five she became unwell, with suspected septicaemia. She was admitted again to the special care unit and was treated with broad spectrum antibiotics. She continued to deteriorate, required ventilation, and developed disseminated intravascular coagulation. She was treated with infusions of platelets, plasma, and fresh blood, with little response.

By day seven she was still being ventilated and had developed hepatomegaly and ascites. On day nine she deteriorated, becoming anuric, severely acidotic, and hypotonic. Cranial ultrasound showed bilateral intraventricular haemorrhage with ventricular dilatation and parenchymal extension. She died the next day.

Pathology. At necropsy the findings were those of massive haemorrhagic necrosis of liver and adrenals, bilateral renal medullary haemorrhage, and bilateral intraventricular haemorrhage with extension into the brain substance on the right side. Multiple fibrin thrombi were present in small pulmonary vessels but there was no associated pulmonary haemorrhage or infarction. 